\title{
Composite Materials Behaviour. Study, Development and Implementation of the Hypoelastic Model
}

\author{
MARCELA SAVA* \\ Politehnica University Timisoara, Department of Mechanics and Strength of Materials, 2 Victoriei Sq., 300006, Timisoara, \\ Romania
}

\begin{abstract}
The purpose of this research is to study and develop the formulation of a rheological law for composite materials with elasto-plastic behaviour in cold compression. Starting from the generally known relationships in literature, the hypoelastic model proposed for the composite materials behaviour (as powder materials) has been developped/explained, ensuring the understanding of the research. The hypolastic theory has been used for modeling the continuous transition from elastic to plastic state for a powder material.The material behaviour is described through an isotropic tensor relationship between the deformation speed tensor, Cauchy's stress tensor and its derivative in relation to time (the Jaumann's derivative). Only the linear part has been used from the general form of the law which depends on scalar functions. The calculations lead to relationships depending on five parameters which are identified according to experimental data. A numerical simulation of the stress-strain evolution during the simple compression of a diepressed powder sample is made; the numerical simulation has been validated by the experimental results.
\end{abstract}

Keywords: composite materials, constitutive model, Cauchy's stress tensor, elastic and plastic behaviour

\section{Introduction}

Composite materials are present in all activity fields and have proven to be a class of materials with high potential in ceramic, pharmaceutical, chemical [1], automotive [2,3], aerospace [4], and electronics industry [5], in medicine [6], defense [7] and in the field of sports equipment manufacturing. Metal matrix composites represent $10 \%$ of the production of composite materials; as matrix metals are chosen $\mathrm{Al}, \mathrm{Ti}, \mathrm{Mg}, \mathrm{Ni}, \mathrm{Cu}, \mathrm{Fe},[8]$. Specific processes of powder metallurgy are used for the elaboration of composites materials [9]. The cold pressing process is of great importance in the manufacturing of the powder materials [10]. The powders densification involves a metalurgical aspect and a mechanical one. From a mechanical point of view, the densification comes from the plastic deformation of cold compressed particles and from the viscoplastic deformation of the sintered particles. The study of the mechanical behavior of the cold pressed powders is important to predict the response of the powder material in terms of stresses and strains [11-16].

Metal powders have an elasto-plastic behaviour during compaction, and is very difficult to identifie the elastic behaviour zone and the plastic one; the size of these zones evolves during powder compaction. Modeling the transition from elastic to plastic state is a challenging research issue; some authors work on the estimation of the relative density corresponding to the transition from the elastic to plastic state affected by the particle size [17]; other authors focus their work on a densification equation derived from deformation occurring in the powder mix during cold compaction, having a physical meaning also individuating the parameters describing the densification behaviour and in turn the compressibility of the different powders investigated [18]. Other researchers study the evolution of elastic strains vs. applied stress with the presence of phase-specific elasto-plastic regimes. The nature of the elasto-plastic transition is uncovered by the "tangent modulus" analysis and correlated to the microstructure of the studied nanocomposite. A new criterion for the determination of the macroyield stress is given as the stress to which the macroscopic work hardening becomes smaller than one [19].

\footnotetext{
*email:marcela.sava@upt.ro
} 
Satisfactory models describing densification were proposed as the result of the axial and radial stresses acting on the powder column. The recorded data are very precise from an industrial perspective mainly in the last stage of compaction directly related to final green density [20].

An original approach is based on an incremental variational principle according to which the local stress-strain relation derives from a single incremental potential constructed from a free energy and a dissipation function [21].

In this paper, the mechanical behaviour of powder materials is described through a constitutive model. An analytical elastic theory or a rigid-plastic scheme will idealize the powder behaviour. Stutz's [22] hypolastic theory has been used for modeling the continuous transition from elastic to plastic state for an iron powder. From the most general form of the Stutz's constitutive model which depends on ten scalar functions is utilized only the linear part, having as arguments the independents invariants of the Cauchy's stress tensor, of deformation speed tensor and the powder relative density. Imposing the condition of homogeneity in relation to time and using a particular issue for the scalar functions, the constitutive model is finally based on five parameters $\alpha_{i}$ depending on the stress tensor invariants and on the powder relative density. The $\alpha_{i}$ functions are identified for an iron powder, by imposing as the constitutive model could describe a linear elastic behaviour for infinitesimal deformations and a perfect plastic behaviour for large deformations.

\section{Materials and methods}

\subsection{Theoretical part}

The hypoelastic model

The quasi linear part of the most general form of Stutz's hypoelastic model, [1] is:

$$
\hat{\sigma}=a_{0} \underset{\sim}{\delta}+a_{1} \underset{\sim}{\sigma}+\underset{\sim}{a_{2}} \underset{\sim}{d}
$$

$a_{0}, a_{1}, a_{2}-$ scalar functions of the invariants of $\sigma$ and $\mathrm{d}$.

The simplified form of the hypoelastic model written in rheological axes is given by:

$$
\hat{\sigma}=\left(\alpha_{0} E_{1}+\alpha_{3} \bar{M}\right) \underset{\sim}{\delta}+\alpha_{1} \underset{\sim}{\dot{\varepsilon}}+\left(\alpha_{2} E_{1}+\alpha_{4} \bar{M}\right) \underset{\sim}{\sigma}
$$

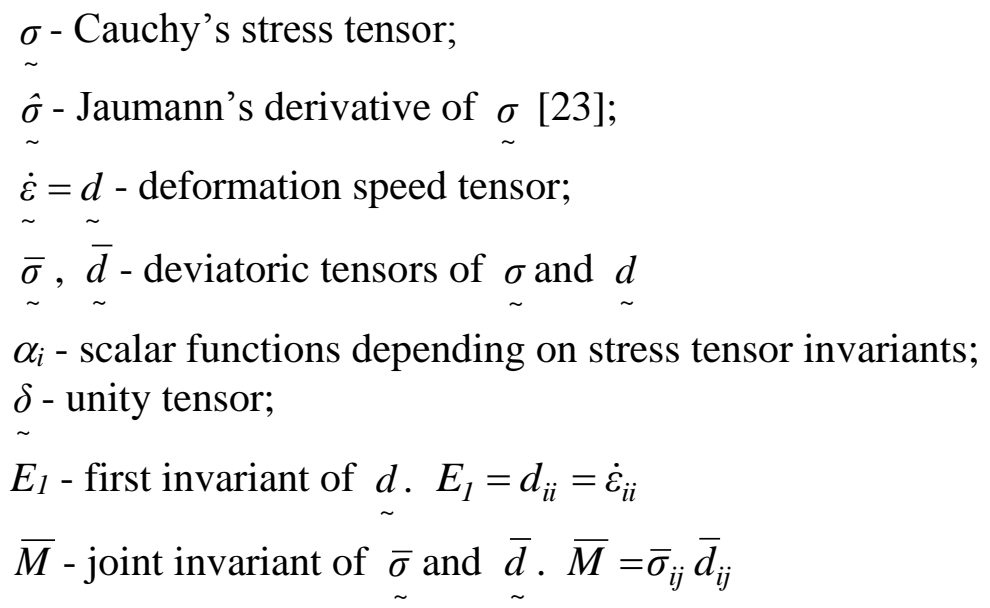

The constitutive law (2) can be decomposed in the isotropic part (3) and a deviatoric part (4), such as:

$$
\hat{S}_{1}=\left(3 \alpha_{0}+\alpha_{1}+\alpha_{2} S_{1}\right) E_{1}+\left(3 \alpha_{3}+\alpha_{4} S_{1}\right) \bar{M}
$$




$$
\begin{aligned}
\underset{\sim}{\hat{\bar{\sigma}}=\alpha_{1}} \dot{\bar{\varepsilon}}^{\dot{\varepsilon}}+\left(\alpha_{2} E_{1}+\alpha_{4} \bar{M}\right) \bar{\sim} \\
\underset{\sim}{\bar{\sigma}}=\underset{\sim}{\sigma}-\frac{1}{3} S_{1} \delta \\
\underset{\sim}{\hat{\bar{\sigma}}}=\underset{\sim}{\hat{\sigma}}-\frac{1}{3} \hat{\sim}_{1} \underset{\sim}{\delta}
\end{aligned}
$$

Introducing (2) and (3) in (6) and, we have:

$$
\frac{\hat{\bar{S}}_{2}^{2}}{2}=\alpha_{2} E_{1} \bar{S}_{2}^{2}+\left(\alpha_{1}+\alpha_{4} \bar{S}_{2}^{2}\right) \bar{M}
$$

with: $S_{1}=3 P$ - first invariant of $\sigma$

$S_{2},-$ second invariant of $\bar{\sigma}$

$\bar{S}_{2}^{2}=\bar{\sigma}_{i j} \bar{\sigma}_{i j}$

$\hat{\bar{S}}_{2}^{2}=2 \hat{\bar{\sigma}}_{i j} \bar{\sigma}_{i j}$

$\bar{M}=\overline{\dot{\varepsilon}} \bar{\sigma}$

To a plastic state, $S_{1}=$ constant, $\bar{S}_{2}^{2}=$ constant, $\hat{S}_{1}=0, \hat{\bar{S}}_{2}^{2}=0, \dot{\varepsilon} \neq 0$,

(3) and (7) will give (8):

$$
\left(3 \alpha_{0}+\alpha_{1}\right)\left(\alpha_{1}+\alpha_{4} \bar{S}_{2}^{2}\right)+\alpha_{2}\left(\alpha_{1} S_{1}-3 \alpha_{3} \bar{S}_{2}^{2}\right)=0
$$

Considering the simple compression, $\sigma_{\mathrm{z}} \neq 0, \sigma_{r}=0$ and (2) becomes (9) and (10):

$$
\begin{aligned}
& \hat{\sigma}_{z}=\left(\alpha_{0} E_{1}+\alpha_{3} \bar{M}\right)+\alpha_{1} \dot{\varepsilon}_{z}+\left(\alpha_{2} E_{1}+\alpha_{4} \bar{M}\right) \sigma_{z} \\
& \sigma_{r}=O \Rightarrow \hat{\sigma}_{r}=O \Rightarrow\left(\alpha_{0} E_{1}+\alpha_{3} \bar{M}\right)+\alpha_{1} \dot{\varepsilon}_{r}=O
\end{aligned}
$$

$\sigma_{z}, \sigma_{r}$ - axial and radial normal stresses;

$\varepsilon_{z}, \varepsilon_{r}$ - axial and radial strains;

$$
\begin{gathered}
E_{l}=\dot{\varepsilon}_{z}+2 \dot{\varepsilon}_{r} ; \\
\bar{M}=\bar{\sigma}_{i j} \bar{d}_{i j}=\frac{2}{3} \sigma_{z}\left(\dot{\varepsilon}_{z}-\dot{\varepsilon}_{r}\right) .
\end{gathered}
$$

Introducing $E_{l}$ and $\bar{M}$ in (10), the Poisson's ratio ( $v$ ) can be calculated:

$$
\frac{\dot{\varepsilon}_{r}}{\dot{\varepsilon}_{z}}=\frac{-\left(\alpha_{0}+\frac{2}{3} \alpha_{3} \sigma_{z}\right)}{2 \alpha_{0}+\alpha_{1}-\frac{2}{3} \alpha_{3} \sigma_{z}}=-v
$$




\section{Results and discussions}

\subsection{Calculus and identification of the parameters $\alpha_{i}$. Numerical simulation}

Hypothesis: at the plastic state, we consider $v=v_{p}=$ constant (we consider $v_{p}=0,45$ - Figure 2 [24]) and $\sigma_{z}=\sigma_{z p}\left(\sigma_{z p}=\right.$ axial normal stress at the plastic state). The value of $v_{p}$ is determined using the experimental curves (Figures 1,2). Figure 1 shows the experimental axial normal compaction stress $\left(\sigma_{z}\right)$ versus axial strain $\left(\varepsilon_{z}\right)$ to the plastic state. A die-compressed iron sample, precompacted to a relative density $\rho=0,9$ was used. Simple compression tests (loading-unloading) were carried out, as shown in Figure 1. The "P" curve (for the plastic state) was obtained by substracting the elastic part from the simple compression curves "SC" [24]; $\sigma_{z} \cong 210 M P a$ on the „P" curve. The elasticity modulus $E_{0}$ is calculated as the slope of the linear part of "P" curve: $E_{0}=81598 \mathrm{MPa}$.

Figure 2 shows the axial normal compaction stress $\left(\sigma_{z}\right)$ versus axial strain $(\varepsilon)$ in simple compression at the plastic state, for different Poisson's ratios values $\left(v_{0}\right)$.

\subsection{Calculus of the parameters $\alpha_{0}$ and $\alpha_{1}$}

The relationship (13), written at the plastic state (with the Poisson's ratio $v=v_{\mathrm{p}}$ ) gives $\alpha_{3}$ :

$$
\alpha_{3}=\frac{3}{2} \frac{\left(2 \alpha_{0}+\alpha_{1}\right) v_{p}-\alpha_{0}}{\left(1+v_{p}\right) \sigma_{z p}}
$$

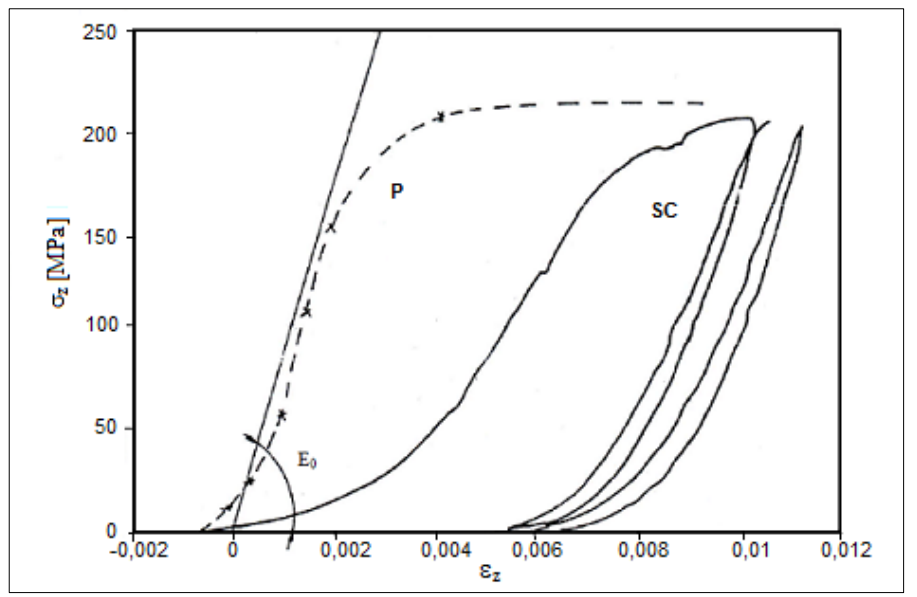

Figure 1. Experimental stress-strain distribution

for simple compression (to the plastic state)

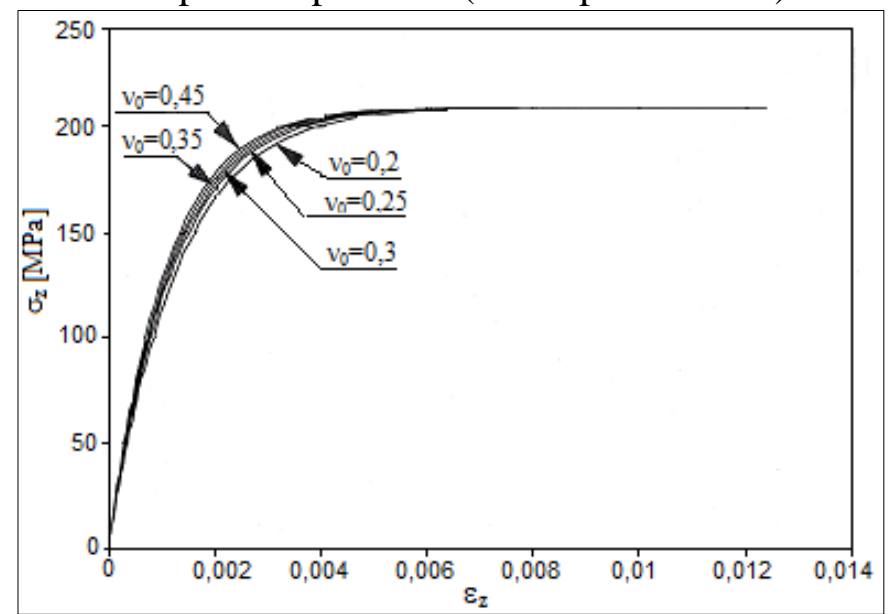

Figure 2. Experimental stress-strain distribution for simple compression (for different Poisson's ratios values) 
If (14) is substituted to (8), using $S_{1}=\sigma_{z p}$ and $\bar{S}_{2}^{2}=\frac{2}{3} \sigma_{z}^{2}$ for the simple compression, $\alpha_{4}$ can be calculated:

$$
\alpha_{4}=\frac{\alpha_{2} \sigma_{z p}\left(2 v_{p}-1\right)-\alpha_{1}\left(1+v_{p}\right)}{\frac{2}{3} \sigma_{z p}^{2}\left(1+v_{p}\right)}
$$

The relationships (9) and (13) give (16), where $\alpha_{3}$ and $\alpha_{4}$ are given by (14) and (15):

$$
\hat{\sigma}_{z}=\dot{\varepsilon}_{z} \frac{\alpha_{1}\left(3 \alpha_{0}+\alpha_{1}\right)+\alpha_{1} \alpha_{2} \sigma_{z}+\frac{2}{3} \sigma_{z}^{2}\left[\alpha_{4}\left(3 \alpha_{0}+\alpha_{1}\right)-3 \alpha_{2} \alpha_{3}\right]}{2 \alpha_{0}+\alpha_{1}-\frac{2}{3} \alpha_{3} \sigma_{z}}
$$

If the powder material has infinitesimal deformations, the deformation speed vector components $d_{i j}$ are not too different from the derivatives in relation to time of the deformation components $\varepsilon_{i j}$. Considering the powder material in a neutral state, $\sigma_{z}=0$ (at the beginning of the "P" curve), the classical relation of elasticity (Hooke's law) is found; (16) becomes (17):

Hooke's law and (17) give:

$$
\begin{gathered}
\hat{\sigma}_{z}=\dot{\varepsilon}_{z} \frac{\alpha_{1}\left(3 \alpha_{0}+\alpha_{1}\right)}{2 \alpha_{0}+\alpha_{1}} \\
\hat{\sigma}_{z}=E_{0} \dot{\varepsilon}_{z} \\
E_{0}=\frac{\alpha_{1}\left(3 \alpha_{0}+\alpha_{1}\right)}{2 \alpha_{0}+\alpha_{1}}
\end{gathered}
$$

$E, E_{0}$ - Young modulus;

with Lame's parameters and $v_{p}=v_{0}$ :

$$
E=\frac{\mu(3 \lambda+2 \mu)}{(\lambda+\mu)}, \quad v_{0}=\frac{\lambda}{2(\lambda+\mu)}
$$

Finding Hooke's law suggests to interpret the parameters $\alpha_{l}$ and $\alpha_{0}$ like Lame's parameters $\left(\alpha_{l}=2 \mu\right.$, $\left.\alpha_{0}=\lambda\right)$. Then:

$$
\begin{array}{r}
v_{0}=\frac{\alpha_{0}}{2\left(\alpha_{0}+\frac{\alpha_{1}}{2}\right)} \\
\Rightarrow \alpha_{1}=\alpha_{0}\left(\frac{1-2 v_{0}}{v_{0}}\right)
\end{array}
$$

$\alpha_{1}$ from (21) substituted to (18) gives $\alpha_{0}$ :

$$
\alpha_{0}=\frac{E_{0} v_{0}}{\left(1+v_{0}\right)\left(1-2 v_{0}\right)}
$$

The relationships (21) and (22) give the values of the parameters $\alpha_{0}$ and $\alpha_{1}$ (Table 1), for different experimental values of $v_{0} ; E_{0}=81598 \mathrm{MPa}, \sigma_{z} \cong 210 \mathrm{MPa}$ - from the Figure 2 .

Table 1. The values of some parameters $\alpha_{i}$

\begin{tabular}{|c|c|c|c|}
\hline$\nu_{0}$ & $\alpha_{0}(\mathrm{MPa})$ & $\alpha_{1}(\mathrm{MPa})$ & $\alpha_{2}$ \\
\hline 0.2 & 22666 & 67998 & -107.85 \\
\hline 0.25 & 32639 & 65278 & -130.5 \\
\hline 0.3 & 47075 & 62767 & -164.5 \\
\hline 0.35 & 70516 & 60442 & -221.2 \\
\hline 0.45 & 253235 & 56274 & -674.5 \\
\hline
\end{tabular}




\subsection{Calculus of the parameter $\alpha_{2}$}

For the isotropic compression, $\overline{\mathrm{M}}=0$; (3) becomes (23):

$$
\hat{S}_{1}=\left(3 \alpha_{0}+\alpha_{1}+\alpha_{2} S_{1}\right) E_{1}
$$

The isotropic part of the Jaumann's derivative of $\sigma$ (23) gives:

$$
\begin{gathered}
\frac{d P}{d \rho}=\frac{\left(3 \alpha_{0}+\alpha_{1}+\alpha_{2} \cdot S_{1}\right)}{3 \rho}=m \\
\alpha_{2}=\frac{3 m \rho-3 \alpha_{0}-\alpha_{1}}{S_{1}}
\end{gathered}
$$

$\mathrm{m}$-the slope of the experimental isotropic compression curve [25], (Figure 3);

$$
S_{1}=3 P, m=\frac{d P}{d \rho} .
$$

$\rho$ - relative density of the die-compressed iron sample, before simple compression.

Figure 3 shows the experimental results of isotropic compression - average pressure versus relative density. There are many curves fitted on the experimental results of the Figure 3:

$$
\begin{aligned}
& P=1813.13-5597.51 \rho+4461.65 \rho^{2} \\
& P=-5444.98+23119.3 \rho-33190.9 \rho^{2}+16364 \rho^{3} \\
& P=742.082 \rho^{6,08226}
\end{aligned}
$$

We have used the second degree polynome; (24) becomes (27):

$$
m=\frac{d P}{d \rho}=-5597.51+2(4461.65 \rho)
$$

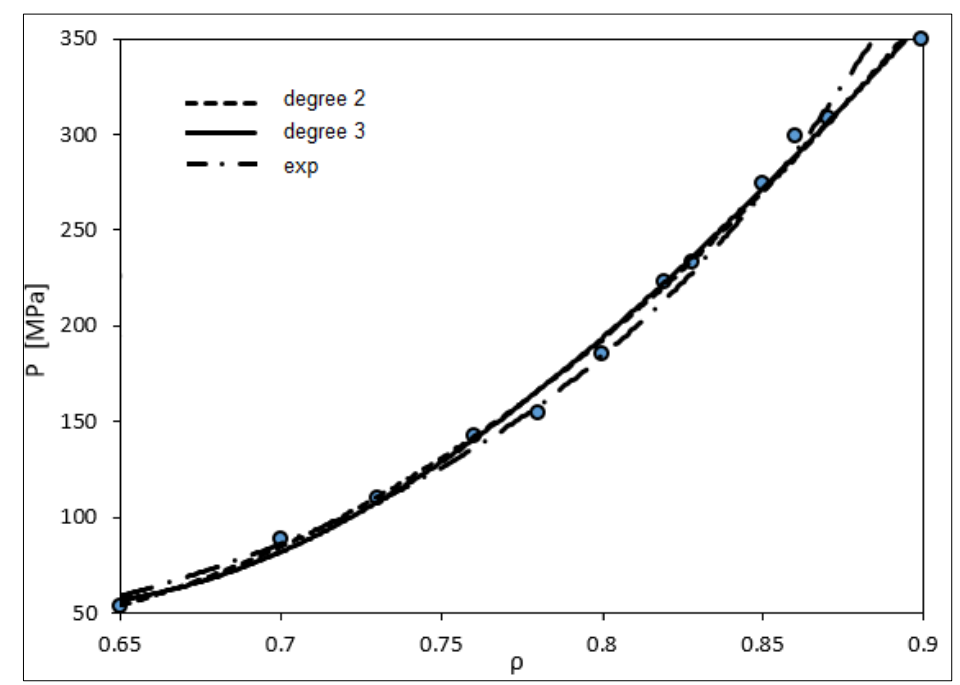

Figure 3. Experimental results of isotropic compression; average pressure versus relative density

For $\rho=0.9, m=2433.46, S_{1}$ and $\alpha_{2}$ can be calculated (Table 1). 


\subsection{Calculus of the parameters $\alpha_{3}$ and $\alpha_{4}$}

We consider a proposed elastoplastic model [9], with the density as the hardening parameter; the yield surface for some density is shown in Figure 4. It should be noted that to each normal stress $\sigma_{z}$ following the straight line of simple compression corresponds a limit value on the yield surface $\left(\hat{\bar{S}}_{2 p}\right)$. The calculus of $\alpha_{3}$ and $\alpha_{4}$ involves some changes in the relationships (14) and (15): $\sigma_{z p}$ will be replaced by $\sigma_{z}$ in (14) and $\sigma_{\text {zp }}^{2}$ will be replaced by $\sigma_{z} \sigma_{p}$ in (15). These values are calculated using the proposed yield surface.

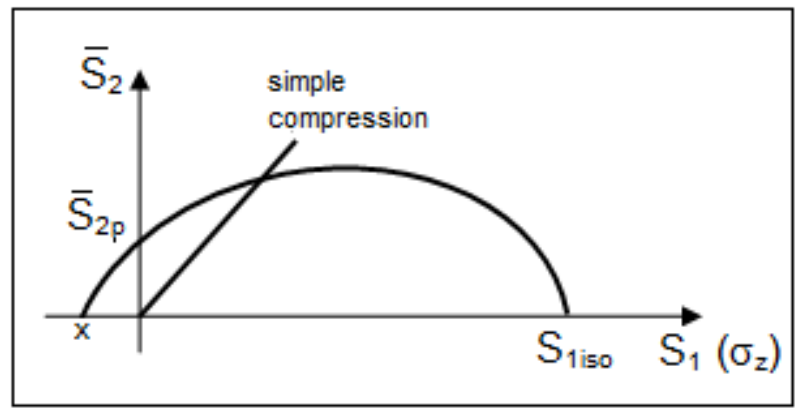

Figure 4. Yield surface

The parameters $\alpha_{3}$ and $\alpha_{4}$ can be calculated using (14) and (15) modified as explained, using the experimental values of $\sigma_{p}, v$, and different values of the normal stress $\sigma_{z}$ for an iron powder.

\subsection{Numerical simulation}

A computer program using the trapezes method is used to integrate the hypoelastic theory (the relationship 16). The evolution of the axial normal stress and strain in simple compression, of a diecompressed iron powder sample was obtained (Figure 5).

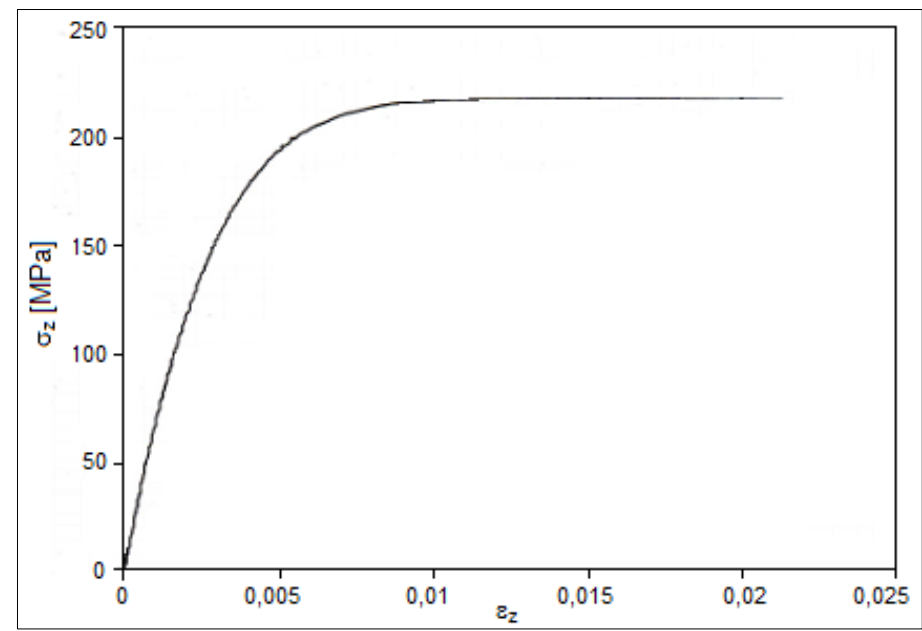

Figure 5. Axial normal compaction stress $\left(\sigma_{z}\right)$ versus axial strain $\left(\varepsilon_{z}\right)$. Numerical simulation of simple compression

\section{Conclusions}

The paper presents an orriginal approach of the continuous transition from elastic to plastic state for a powder material, starting from the hypoelastic model [22]. A development of Stutz criteria (1), based on tensor calculus was performed, using the explicit form of the used tensors and their deviatoric tensors. Under certain original circumstances (the conditions imposed for the simple compression of the powder material in the case of plastic state and the identification of the Poisson's ratio), the relationship (2) allows to describe a perfect plastic flow of the powder material at the critical state. To an appropriate 
and original choice of the $\alpha_{i}$ functions (based on the theoretical and experimental identification of the Hooke's law and Lame's parameters), the relationship (1) will be able to describe the continuous evolution of the material from infinitesimal deformations to large deformations, when the powder material has a perfect plastic behaviour. The validity of the hypoelastic model can be shown by comparing the results of the numerical simulation (Figure 5) with the experimental curve (Figure 1). The numerical simulation is not influenced by the powder relative density. The study of the transition from the elastic to plastic state for powder materials with elasto-plastic behaviour in cold compression is performed differently in literature, as shown in Introduction.

\section{References}

1. MARINESCU, M., et al, Comparative Study of Tensile Behaviour for Layered Polymeric Composite Materials, Mater. Plast., 55(3), 2018, 279-285

2.TANG GU, CASTELNAU O., FOREST S., Multiscale modeling of the elastic behavior of architectured and nanostructured $\mathrm{Cu}-\mathrm{Nb}$ composite wires, International Journal of Solids and Structures, december 2016, 121-131.

3. MARTH, S., HAGGBLAD, H.-A., Oldenburg, M., A comparison between Stepwise Modelling and Inverse Modelling methods for characterization of press hardened sheet metals, Proceedings of the 6th International Conference Hot Sheet Metal Forming of High-Performance Steel CHS2: June 4-7 2017, Atlanta, Georgia, USA, 281-288.

4. PETHO, D., MIKO, T., et al., The Caracterisation of Ceramic Particles Reinforced Molybdenum Composites Produced by Cold Pressing, Proceedings of the Euro PM 2018 Congress, October 14-18 2018, Bilbao, Spain, 201-208.

5. MORARU, C.G., Study, research and contributions regarding the development of some copper based sintered alloys used in the electronics and electrotechnics industry, Teza de doctorat Universitatea Transilvania din Brasov, 2013, 42-48.

6. ANTONIS, S.P., ROZAN, A.E., et al., A Comparative Evaluation of Stress Resistance Between Nanohybrid Composite and Ormocer Restorations on Posterior Teeth - in vitro Study, Mater. Plast., 57(1), 2020, 8-12

7. PETRE, R., ZECHERU, T., et al, Synthesis and Mechanical Properties of Polyurea-Based Hybrid Composites for Ballistic Individual Protection, Mater. Plast., 55(3), 2018, 315-319.

8.WALTHER, G., BUETTNER, T., et al., Iron-Based Sintered Friction Material For Motor Cycles, Proceedings of the Euro PM 2019 Congress, October 13-16. 2019, Maastricht, Netherlands, 165-175.

9. HUTSCH,T., RIESSELMANN, J., et al. Reusable And Lightly Loaded Thermal Interface for Modular Satellites Based on Powder Metallurgically Processed Copper/CNT Composite, Proceedings of the Euro PM 2018 Congress, October 14-18 2018, Bilbao, Spain, 129-136.

10.CRISTOFOLINI, G., In-Situ Analysis of the Powder Behaviour during Cold Compaction, Proceedings of the Euro PM 2014 Congress, September 21-24 2014, Salzburg, Austria, 497-499.

11. BEHRENS, B.A., BOUGUECHA, A., et al. Compaction of a Copper Spiral within A Cylindrical Die Of Steel Powder And Investigation Of Their Deformation Behavior, Proceedings of the Euro PM 2016 Congress, October 9-13 2016, Hamburg, Germany, 157-164.

12. MOLINARI, A, CRISTOFOLINI, I., et al. The Shrinkage of Uniaxially Cold Compacted Iron Green Parts, Proceedings of the Euro PM 2016 Congress, Hamburg Germany, 89-96.

13. SUK HYUN KIM, JIN MO KOO, PARK, S.,J., Development of Regression Model For Iron Powder Compaction Considering on Particle Size Distribution and Copper Content Effects, Proceedings of the Euro PM 2016 Congress, October 9-13 2016, Hamburg Germany, 165-172.

14. CRISTOFOLINI, I., PEDERZINI, G., et al. The Influence of Powder Mix on Densification and Compaction Mechanics in Uniaxial Cold Compaction, Proceedings of the Euro PM 2017 Congress, October 01-04 2017, Milan Italy, 123-130. 
15. FERRARIS, L., POSKOVIC, E., et al. A New Soft Magnetic Composites Material For Electrical Machine: Improvement of Mechanical Properties with High Molding Pressure, Proceedings of the Euro PM 2017 Congress, October 01-04 2017, Milan Italy, 151-157.

16. LINDROOS, M., LAUKKANEN, A., et al. Micromechanical Modeling of Titanium Carbide Composites with High Work Hardening Metal Matrix, Proceedings of the Euro PM 2018 Congress, October 14-18 2018, Bilbao Spain, 137-143.

17. ZAGO, M., CRISTOFOLINI, I., et al. Study of Elasto-Plastic Transition as Affected by Particle Size During Uniaxial Cold Compaction, Proceedings of the Euro PM 2019 Congress, October 13-16 2019, Maastricht, Netherlands, 43-49.

18. CRISTOFOLINI, I., MOLINARI, A., et al. Study of Densification During Uniaxial Cold Compaction of Stainless Steel Powders Through the Analysis of the Stress/Deformation Correlations, Proceedings of the Euro PM 2018 Congress, October 14-18 2018, Bilbao Spain, 71-79.

19. THILLY, L., RENAULT, P.O., et al. A new criterion for elasto-plastic transition in nanomaterials: Application to size and composite effects on $\mathrm{Cu}-\mathrm{Nb}$ nanocomposite wires, Acta materialia 57(11):31573169, 2009.

20. ZAGO, M., CRISTOFOLINI, I., et al., Processing Method to Improve the Reliability of Data Recorded by an Industrial Press in Describing Powder Behavior During Uniaxial Cold Compaction, Proceedings of the Euro PM 2018 Congress, October 14-18 2018, Bilbao Spain, 63-70.

21. BRASSART, L., STAINIER, L., et al., Homogenization of elasto-(visco) plastic composites based on an incremental variational principle, International Journal of Plasticity, september 2012, vol.36, 86112.

22. STUTZ, P., Contribution à l'étude de la loi rhéologique des milieux pulverulents; Thèse de doctorat a l'Université Scientifique et Medicale de Grenoble, 1972, 71-95.

23. JAUMANN, G., Geschlossenes system physickalischer und chemischer differenzialgesetze. Sitzber Akad. Wiss Wien (IIA), 1911, 385-530.

24. MOSBAH, P., Etude experimentale et modélisation du comportement des poudres métalliques au cours du compactage en matrice fermée; Thèse de doctorat a l'Université Joseph Fourier Grenoble I, 1992, 121-138.

25.SAVA, M., Study of Cold Pressed Metal Powders Behaviour, PhD Thesis "Politehnica" University Timisoara, 2003, 45-63

Manuscript received: 23.12 .2020 